\title{
High Expression of Vascular Endothelial Growth Factor in EV71-Infected Patients Does Not Originate from EV71-Infected Cells
}

\author{
Shu-Chen Huang Giri Raghavaraju Hsiao-Sheng Liu \\ Department of Microbiology and Immunology, College of Medicine, National Cheng Kung University, \\ Tainan, Taiwan, ROC
}

\section{Key Words}

Enterovirus · EV71 • Growth factors · Vascular endothelial growth factor

\begin{abstract}
Background: Enterovirus (EV) 71 is an important pathogen causing death in children under 5 years of age worldwide. However, the core pathogenesis remains elusive. We reveal that the protein expression level of vascular endothelial growth factor (VEGF) in EV71 patients was 2-fold higher than in normal controls. However, the origin of VEGF in EV71-infected patients remains unclear. Methods: VEGF mRNA and protein expression in four EV71-infected cell lines was evaluated by RT-PCR, ELISA and Western blotting. Results: We found that only mRNA expression of VEGF was increased in the infected cells. Intra- and extracellular VEGF protein expression was decreased or unchanged in the four infected cell lines compared with the uninfected and inactivated EV71-infected cells. Conclusions: Our data reveal that EV71 infection of four human cell lines induced VEGF mRNA expression but did not induce VEGF protein expression in the infected cells. Therefore, the increased VEGF protein expression in EV71-infected patients may be due to the influence of surrounding non-infected cells following stimulation of proinflammatory cytokines secreted from the infected cells.
\end{abstract}

Copyright $\odot 2010$ S. Karger AG, Basel

\section{Introduction}

Vascular endothelial growth factor (VEGF) is a vascular permeability factor secreted by tumors [1]. The VEGF family consists of six members: VEGF-A, $-\mathrm{B},-\mathrm{C},-\mathrm{D}$ and -E and placental growth factor [2-4], which are responsible for diverse biological functions through interaction with different VEGF receptors. VEGF receptors consist of VEGFR-1, VEGFR-2, VEGFR-3, soluble VEGFR-1, and neuropilins NRP1 and NRP2. The human gene encoding VEGF is located on chromosome 6 and comprises a 14$\mathrm{kb}$ coding region with 8 exons. Alternative splicing of pre-mRNA generates six isoforms, $\mathrm{VEGF}_{121}, \mathrm{VEGF}_{145}$, $\mathrm{VEGF}_{165}, \mathrm{VEGF}_{183}, \mathrm{VEGF}_{189}$ and $\mathrm{VEGF}_{206}$. The purified VEGF is a $46-\mathrm{kDa}$ homodimer.

VEGF plays a critical role in vasculogenesis and is a crucial regulator of vascular development during embryogenesis as well as blood vessel formation under many pathological conditions (for example, tumor growth, rheumatoid arthritis, diabetic retinopathy, chronic inflammation, amyotrophic lateral sclerosis, stroke, ischemic neuropathy, Parkinson's disease, Alzheimer's disease and multiple sclerosis). Many cells can secrete VEGF, such as endothelial and epithelial cells, monocytes, macrophages, T lymphocytes, keratinocytes, fibroblasts, granulocytes, eosinophils and smooth-muscle cells, indicating that VEGFs manipulate diverse physiological

\section{KARGER}

Fax +41613061234 E-Mail karger@karger.ch www.karger.com
Dr. Hsiao-Sheng Liu

Department of Microbiology and Immunology, College of Medicine

National Cheng Kung University

Tainan, Taiwan (ROC)

Tel. +886 6235 3535, ext. 5630, Fax +886 6208 2705, E-Mail a713@mail.ncku.edu.tw 
functions in many cells. In this study, we investigated VEGF-A, which interacts with VEGFR-1, VEGFR-2, and NRP1 and NRP2 [5].

VEGF, the most potent angiogenic protein known $[6$, 7], is a diffusible endothelial cell-specific mitogen and an angiogenic factor which also increases vascular permeability. Endothelial cell survival is VEGF dependent [8]. VEGF overproduction has been identified as a major factor underlying pathological angiogenesis in vivo in diseases such as psoriasis, macular degeneration and tumor proliferation [9]. The increases in lung VEGF content driven by endothelin can contribute to the formation of pulmonary edema, indicating that VEGF overexpression induces acute pulmonary edema [10]. In normal tissues, the most abundant VEGF expression is found in the lung [11]. The symptoms of enterovirus (EV) 71-infected patients include changes in lung cell membrane permeability, pulmonary edema and acute flaccid paralysis. Various experimental and human studies support the concept of VEGF playing a major role in the pathogenesis of highpermeability pulmonary edema [12]. However, whether EV71 infection-related pulmonary edema is caused by VEGF is unclear. Furthermore, if VEGF does indeed play a causal role, it remains to be elucidated whether VEGF is released from EV71-infected cells. This study investigated whether EV71 infection can induce VEGF expression.

VEGF expression is regulated by many factors in non-neuronal cells. One of the important reactions involved in this process is histogenic hypoxia, which links VEGF with angiogenesis. Like other hypoxia-responsive genes, VEGF expression in response to hypoxia can be increased through hypoxia-inducible factor (HIF)-1, which binds to hypoxia response element in the $5^{\prime}$ promoter region of VEGF and regulates VEGF transcription. Furthermore, many growth factors and cytokines regulate VEGF expression, which further promotes angiogenesis and increases vascular permeability during inflammation. Nitric oxide increases VEGF expression by stabilizing HIF-1 protein. In addition, some other cellular stress conditions, such as low blood sugar, acidic conditions and oxidative stress, can also activate VEGF. The transformation-related genes in tumor cells, such as mutant ras [13] and mutant von Hippel-Lindau tumor suppressor gene, also induce tumor growth by activating VEGF.

VEGF and its receptor VEGFR are expressed in neurons and glial cells during embryonic development and in a damaged nervous system. VEGFR is also expressed in endothelial cells. These phenomena imply that VEGF affects peripheral neurons, glial cells and endothelial cells through the autocrine regulation. During embryonic development of the nervous system, vascular sprouts derived from a primitive perineural plexus invade the developing neuroectoderm and then divide to form a network of vessels. Endothelial cells of the perineural plexus and developing capillaries express VEGFR, while VEGF is expressed in the ventricular zone of the neuroectoderm. The spatial and temporal expression patterns of VEGF and its receptors suggest that VEGF may also act in a paracrine fashion to induce the growth of capillaries in the development of the brain.

In developing countries, focal cerebral ischemia and stroke are the major causes of death. One symptom is low blood flow in the brain, which causes a decrease in oxygen, glucose and intracellular energy storage, an imbalance in the ionic gradient, the aggregation of ions, and release of neurotransmitters as well as reactive oxygen species in neurons. The above cytotoxicities induce cerebral edema, open the blood-brain barrier and cause vasogenic edema. Further, in the ischemia core, neurons and glial cells quickly die. In addition, the injury to the central nervous system (CNS) breaks the blood-brain barrier, causes spinal cord inflammation and induces angiogenesis in the damaged CNS. VEGF repairs damaged CNS by changing the permeability of the vessel, neurotropism and angiogenesis in the injured CNS [14].

In summary, VEGF plays several roles which are related to the clinical symptoms of EV71-infected patients. For example, VEGF affects the nervous system and overexpression of VEGF causes pulmonary edema. In this study, we therefore examined whether VEGF originates from EV71-infected cells.

\section{Materials and Methods}

\section{Cell Lines}

Four cell lines, RD (human rhabdomyosarcoma, ATCC CCL136), SK-N-SH (human neuroblastoma, ATCC HTB-11), A549 (human lung carcinoma, ATCC CCL-185) and HMEC-1 (human microendothelial cells), were cultured at $37^{\circ}$ in a $5 \% \mathrm{CO}_{2}$ incubator. $\mathrm{RD}, \mathrm{SK}-\mathrm{N}-\mathrm{SH}$ and A549 cells were maintained in L-glutamine containing Dulbecco's modified Eagle's medium (DMEM; GIBCOBRL, Gaithersburg, Md., USA) supplemented with $10 \%$ fetal bovine serum (FBS; Trace, Sydney, N.S.W., Australia) plus penicillinstreptomycin (200 units/ml), and HMEC-1 cells were maintained in $\mathrm{EGM}^{\mathrm{TM}}$-2 medium (Cambrex Bio Science, Rockland, Me., USA).

Virus

EV71 4643 strain was isolated from an 18-month-old patient who died of encephalitis in Taiwan. RD cells were used for EV71 
infection. Virus-infected cells were maintained in a $5 \% \mathrm{CO}_{2}$ incubator at $37^{\circ}$ until cytopathic effects were evident. Finally, cells were frozen and thawed between -70 and $37^{\circ}$ three times and the culture media were collected. EV71 titer was determined by plaque assay and the virus was stored at $-70^{\circ}$ for further use.

\section{RT-PCR}

Two micrograms of RNA, oligo(dT) $)_{15}$ and DEPC-MQ $\mathrm{H}_{2} \mathrm{O}$ in a total of $5 \mu \mathrm{l}$ of solution were incubated at $70^{\circ}$ for $5 \mathrm{~min}$ and then at $4^{\circ}$ for $5 \mathrm{~min}$. The RNA mixture was mixed with $1 \times$ reaction buffer, $\mathrm{MgCl}_{2}(1.5 \mathrm{mM}), 1 \mu \mathrm{l}$ recombinant RNasin, $0.5 \mu$ l reverse transcriptase (Promega, Madison, Wisc., USA) and $0.5 \mathrm{mM} \mathrm{dNTP}$, and incubated at $25^{\circ}$ for $5 \mathrm{~min}, 42^{\circ}$ for $60 \mathrm{~min}$ and $70^{\circ}$ for $25 \mathrm{~min}$, and then stored at $4^{\circ}$. The cDNA was amplified in a PCR thermal cycler for $2 \mathrm{~min}$ at $94^{\circ}$, followed by 32 cycles of $1 \mathrm{~min}$ at $94^{\circ}, 1 \mathrm{~min}$ at $60^{\circ}, 1 \mathrm{~min}$ at $72^{\circ}$ and finally $10 \mathrm{~min}$ at $72^{\circ}$. The primers used for PCR were as follows: VEGF (forward) $5^{\prime}$-AGCTACTGCCATCCAATCGC-3', VEGF (reverse) 5'-GGGCGAATCCAATTCCAAGAG-3', $\beta$-actin (forward) $5^{\prime}$-TGGAATCCTGTGGCATCCATGAAAC- $3^{\prime}$ and $\beta$-actin (reverse) $5^{\prime}$-TAAAACGCAGCTCAGTAACAGTCCG-3' . The expression level of $\beta$-actin was used as a normalization control.

\section{Cell Lysis}

Cell lysates were prepared as described previously [15]. Briefly, cells were washed twice with ice-cold PBS and lysed with $200 \mu \mathrm{l}$ (per 10-cm plate) of whole-cell extract lysis buffer (50 mM Tris, pH 7.4, 1\% NP40, 2 mM EDTA, $100 \mathrm{~mm} \mathrm{NaCl}, 10 \mathrm{~mm} \mathrm{Na}_{3} \mathrm{VO}_{4}$, $0.1 \%$ SDS, $10 \mathrm{mg} / \mathrm{ml}$ leupeptin, $2 \mathrm{mg} / \mathrm{ml}$ aprotinin and $100 \mathrm{~mm}$ phenylmethylsulfonyl fluoride; protease inhibitors from Roche Applied Sciences, Indianapolis, Ind., USA). Cell lysates were further cleaned using centrifugation at $14,000 \mathrm{rpm}$ for $15 \mathrm{~min}$. Protein concentration was determined using a Bradford assay (BioRad, Richmond, Calif., USA).

\section{Western Blot Analysis}

Equal amounts of cell lysates were boiled for 5 min with the sample buffer before separation on an SDS-polyacrylamide gel. The proteins in the gel were transferred onto a PVDF membrane (Millipore, Billerica, Mass., USA) in Tris-glycine buffer at $100 \mathrm{~V}$ for $1.5 \mathrm{~h}$ using an electroblotter (Amersham Biosciences, Piscataway, N.J., USA). Membranes were blocked with PBS buffer containing $5 \%$ nonfat milk before incubating with antibodies. The target protein binding the specific antibody was detected by enhanced chemiluminescence according to the manufacturer's recommendations (Millipore).

\section{RNA Extraction}

Total RNA was extracted using a single-step method with TRIzol reagent (Invitrogen, Carlsbad, Calif., USA). For RT-PCR, first-strand cDNA was synthesized from 0.2 to $1 \mu \mathrm{g}$ of total RNA with an oligo(dT) primer and the Moloney murine leukemia virus reverse transcriptase (Promega).

\section{ELISA}

Capture antibody $100 \mu \mathrm{l}$ (R\&D Systems, Minneapolis, Minn., USA) was added into the 96 -well plate overnight. After washing with $400 \mu \mathrm{l}$ of washing buffer three times, the plate was incubated with $300 \mu$ l blocking buffer for $1 \mathrm{~h}$ at room temperature (RT). Subsequently, the plate was incubated with $100 \mu$ l of sample or

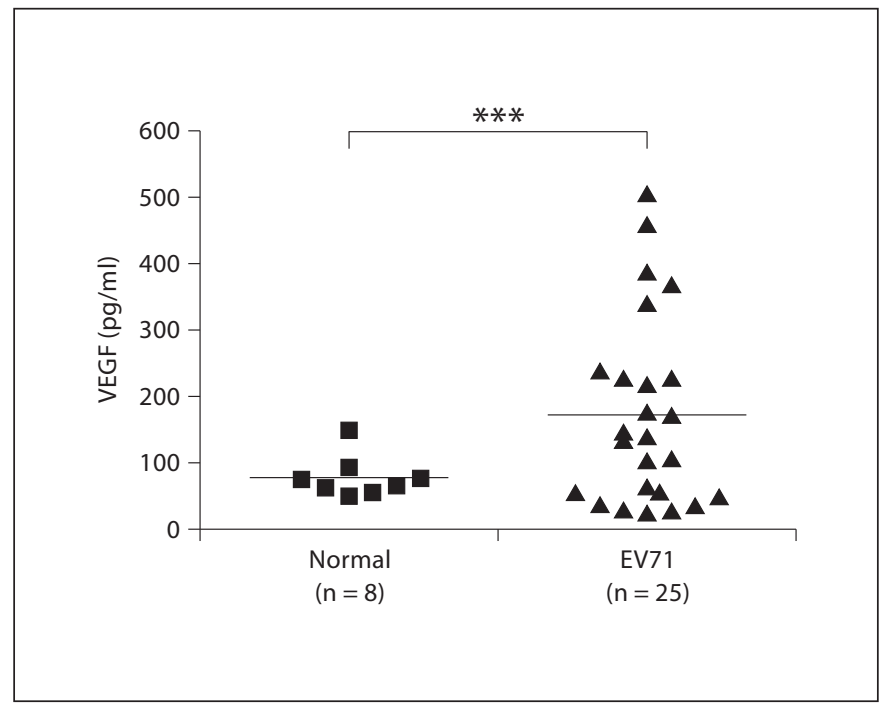

Fig. 1. Detection of VEGF levels in the sera (50 $\mu \mathrm{l} /$ each) of $25 \mathrm{EV} 71$ patients and 8 normal controls by ELISA. ${ }^{* * *} \mathrm{p}<0.001$ (Student's $\mathrm{t}$ test).

standard solution for $2 \mathrm{~h}$ at RT, $100 \mu \mathrm{l}$ of detection antibody for $2 \mathrm{~h}$ at RT, $100 \mu \mathrm{l}$ of streptavidin-HRP for $20 \mathrm{~min}$ at RT and $100 \mu \mathrm{l}$ tetramethylbenzidine (Pierce, Minneapolis, Minn., USA) for 20 min at RT, with each incubation step being preceded by three washing steps. Finally, $50 \mu \mathrm{l}$ of stop solution was added. The optical density at a wavelength of 450-540 nm (or $570 \mathrm{~nm}$ ) was measured using a $V_{\max }$ microplate reader (Molecular Devices, Sunnyvale, Calif., USA).

\section{Statistical Analysis}

Differences between the test and control groups were analyzed using Student's t test. Significance was set at $\mathrm{p}<0.05, \mathrm{p}<0.01$ and $\mathrm{p}<0.00$.

\section{Results}

Secretion Levels of VEGF in the Sera of EV71 Patients The pathogenetic mechanism underlying EV71-induced neural and pulmonary edema syndromes in EV71infected patients remains unclear. Previous studies indicate that VEGF is involved in the pathological changes of neurons and the increase in membrane permeability. To clarify whether VEGF participates in the pathogenesis of EV71-infected patients, the patients' expression level of VEGF was measured by ELISA. Serum VEGF was at least two-fold higher in EV71 patients than in the controls (fig. 1). Our data suggest that VEGF overexpression resulted from EV71-infected cells. 
$\mathrm{RD}$
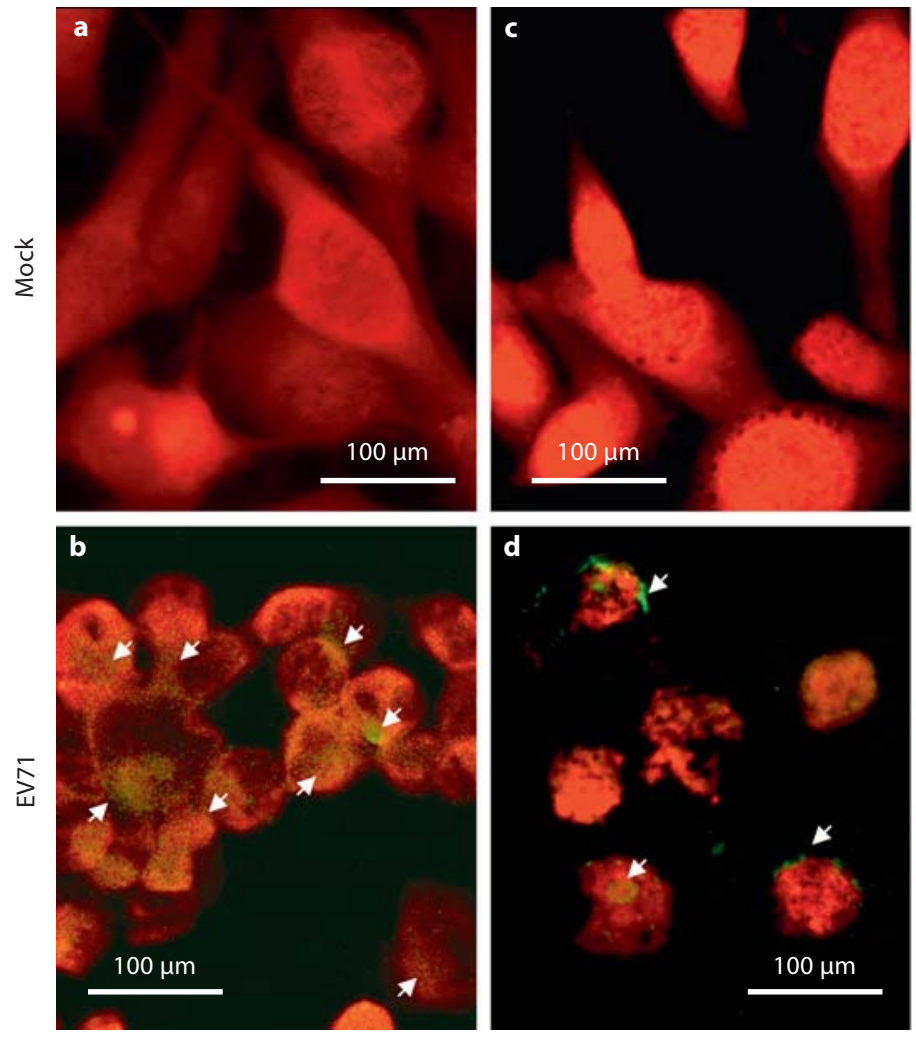

SK-N-SH

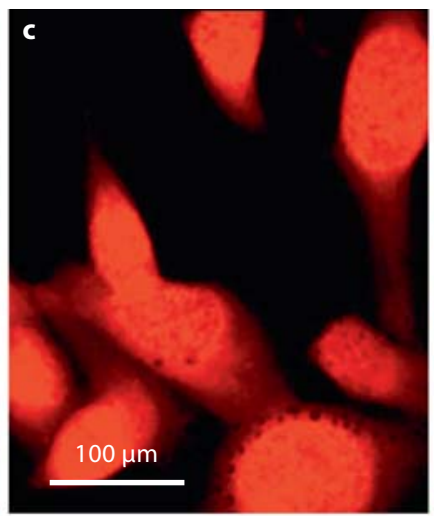

A549
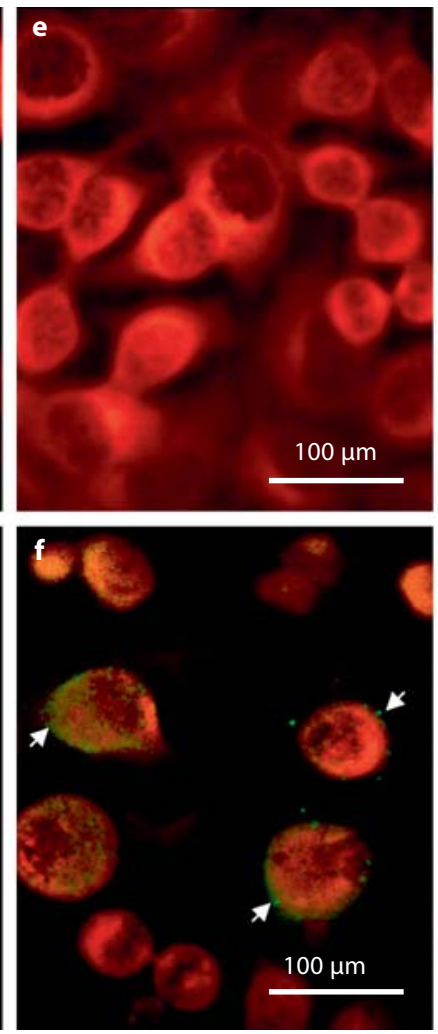

HMEC-1
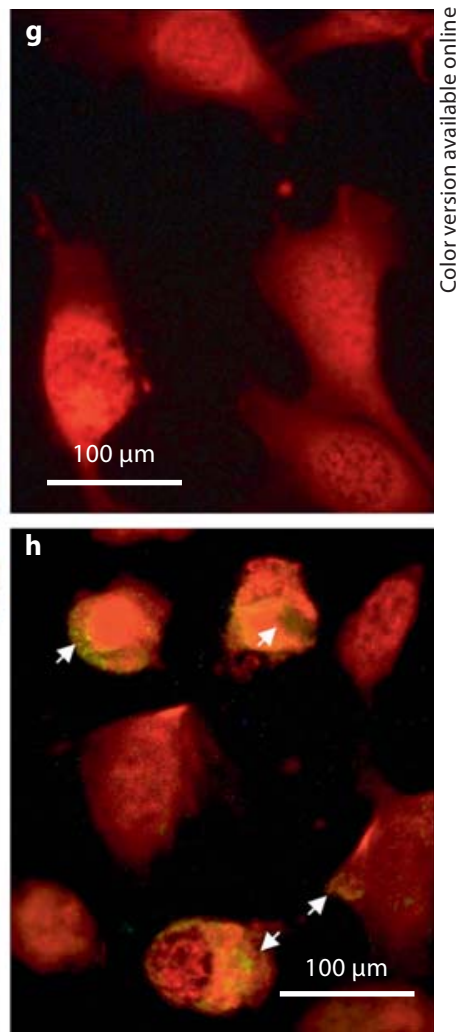

Fig. 2. Detection of EV71 infection in four cell lines under a fluorescence microscope. EV71 was used to infect RD, SK-N-SH and A549 cells at MOI 1 and HMEC- 1 cells at MOI 5 for 18 h. a, b RD cells. c, d SK-N-SH cells. e, f A549 cells. g, h HMEC-1 cells. Cells were either infected with EV71 (b, d, f, h) or with 2\% FBS-DMEM (a, c, e, g) for $1 \mathrm{~h}$, and then labeled with FITC-conjugated antiEV71 antibody 3324 (Chemicon, Temecula, Calif., USA) to detect EV71 (arrow; online version: green). Evan's blue was used as a counter stain of the cell (online version: red).

\section{Permissive Infection of the EV71 4643 Strain}

in Four Cell Lines Demonstrated by Indirect

Immunofluorescent Assay

To determine whether the increased VEGF expression was from EV71-infected cells, four cell lines were investigated, RD, SK-N-SH, A549 and HMEC-1, after EV71 infection. EV71 indeed infected and replicated in all of these cell lines, which was demonstrated by immunofluorescent staining of the virus with FITC labeling (fig. 2). Our data show that these cell lines are permissive to EV71 4643 strain infection.

\section{Expression of Two VEGF mRNA Isoforms and Protein} in EV71 4643 Strain-Infected Cells

The expression levels of two endogenous VEGF mRNA isoforms (165 and 121) and protein as well as the secretion of VEGF protein in the four cell lines after EV71 infection were assessed by RT-PCR, Western blot- ting and ELISA. The two endogenous VEGF mRNA isoforms (165 and 121) were overexpressed $6 \mathrm{~h}$ after infection in SK-N-SH (fig. 3b), 6-12 h after infection in A549 cells (fig. 3c) and $12 \mathrm{~h}$ after infection in RD and HMEC1 cells (fig. $3 \mathrm{a}, \mathrm{d}$ ). Our data reveal that virus infection induced VEGF mRNA expression in various infected cell lines at different times after infection. The expression levels of VEGF protein in the four EV71-infected cell lines were further evaluated by Western blotting (fig. 4). VEGF protein levels were decreased in RD (fig. 4a), SK$\mathrm{N}-\mathrm{SH}$ (fig. 4b) and HMEC-1 (fig. 4d) cells $12 \mathrm{~h}$ after infection and in A549 cells (fig. 4c) 6 and $12 \mathrm{~h}$ after infection. To determine whether the decreased protein expression inside the cells was caused by VEGF secretion, VEGF secretion was evaluated in the uninfected cell lines and in the cell lines infected with EV71 or inactive EV71 by ELISA. VEGF secretion was decreased in EV71infected RD and SK-N-SH cells compared with uninfect- 


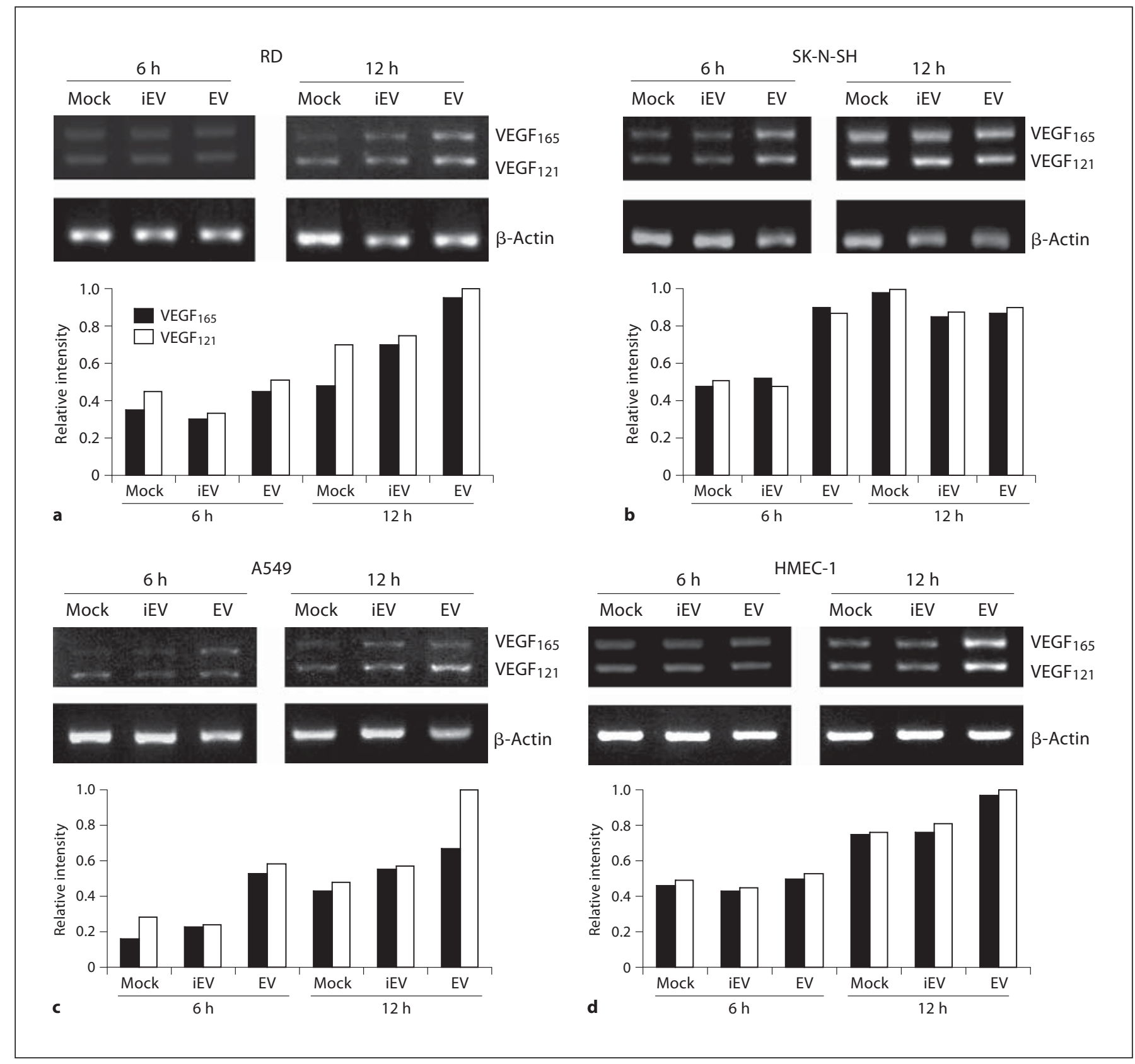

Fig. 3. Detection of VEGF mRNA expression in the cells infected with EV71 by RT-PCR. Total RNA was extracted from the cells followed by RT-PCR using VEGF-specific primers, which were used to evaluate the levels of two isoforms (165 and 121) of VEGF expression in RD (a), SK-N-SH (b), A549 (c), and HMEC-1 cells (d) at constant intervals after infection. The expression level of $\beta$ actin was used as an internal control and for normalization of VEGF expression. iEV = Heat-inactivated EV71. ed cells or cells infected with inactive EV71 (fig. 5a, b). VEGF secretion was increased in A549 cells in a timedependent manner with or without EV71 infection (fig. 5c). VEGF secretion fluctuated in HMEC-1 cells infected either with active or inactive EV71 or in mock- infected cells, indicating that EV71 had no effect on VEGF secretion (fig. 5d).

In summary, our data suggest that EV71 infection did not result in increased VEGF synthesis and secretion at translational level in EV71-infected cells. 


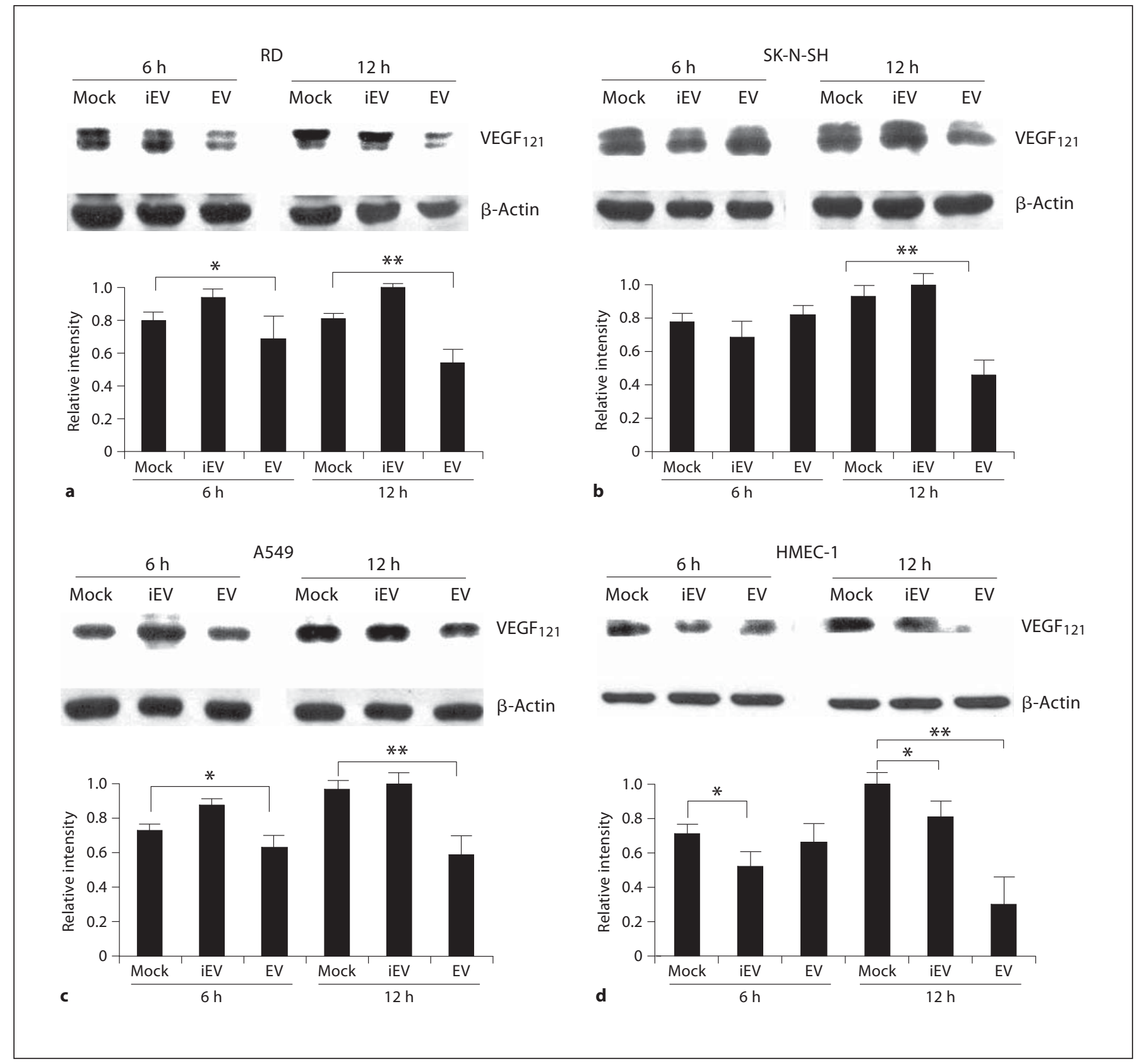

Fig. 4. Detection of VEGF protein expression in the cells infected with live EV71, heat-inactivated EV71 (iEV) or mock infection by Western blotting. Total protein was collected from RD (a), SK-NSH (b), A549 (c) and HMEC-1 cells (d) at constant intervals after infection, and VEGF expression was evaluated by Western blotting using anti-VEGF 121 antibody. $\beta$-Actin was used as an internal control. This experiment was repeated three times. ${ }^{*} \mathrm{p}=0.05$, ${ }^{* *} \mathrm{p}=0.01$ (Student's t test).

\section{Discussion}

Pulmonary edema has been classified into two categories: cardiogenic pulmonary edema (CPE) and neurogenic pulmonary edema (NPE). CPE is caused by heart dam- age which leads to transudation of the fluid into the pulmonary interstitium and alveoli. The increase in the left atrium pressure leads to an increased lung microvasculature pressure $(>18 \mathrm{~mm} \mathrm{Hg})$ and results in pulmonary edema. NPE is caused by the injury of neurons. A severe 


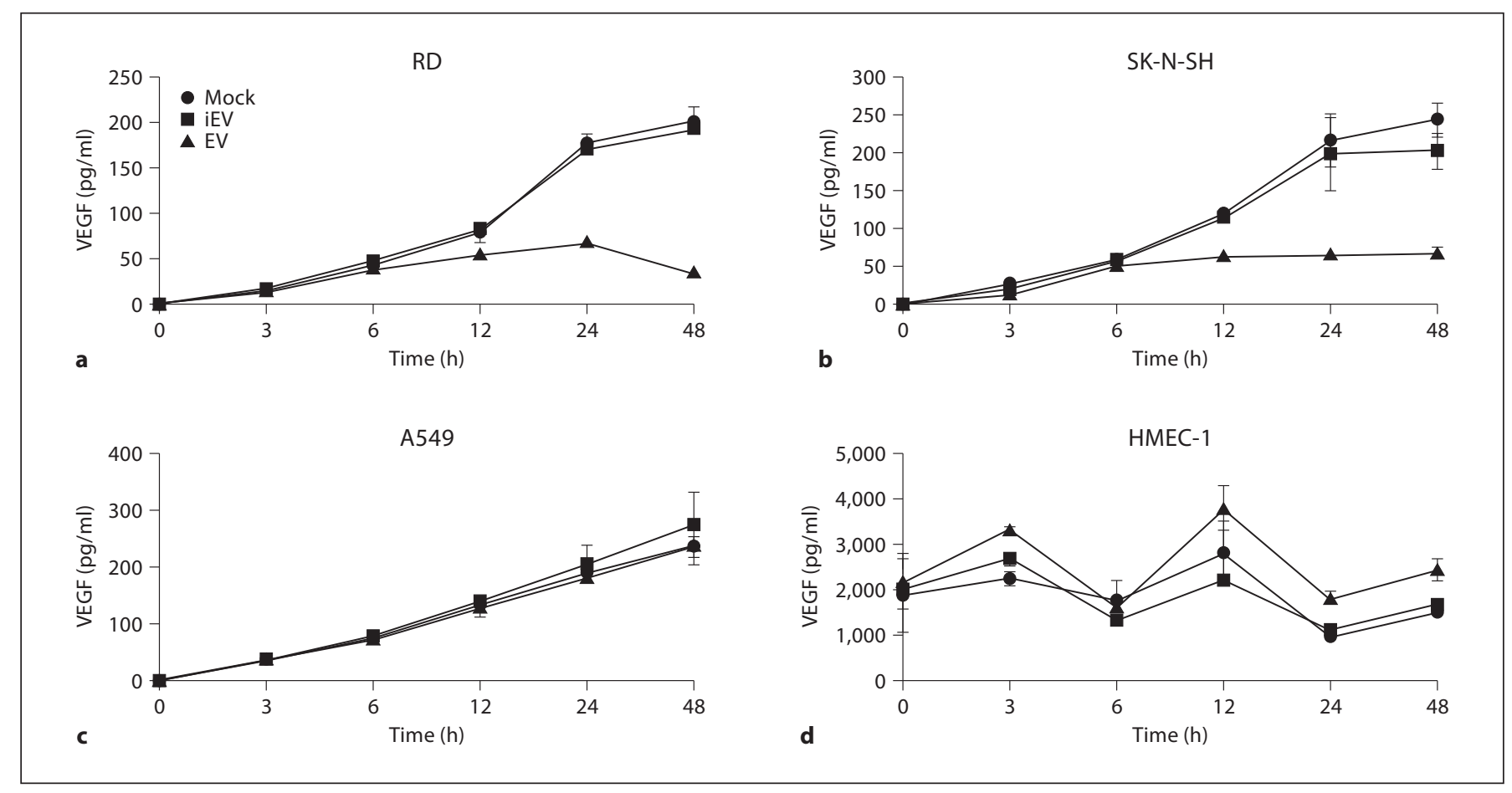

Fig. 5. Detection of the expression level of VEGF secreted from the cells infected with live EV71, heat-inactivated EV71 (iEV) or mock infection by ELISA. Unbound viruses were removed by washing with $10 \%$ FBS-DMEM. The supernatants of the treated cells were collected $(100 \mu \mathrm{l})$ at constant intervals after infection followed by ELISA. outbreak of EV71 infection occurred in Taiwan in 1998, and many patients showed symptoms of acute flaccid paralysis and died of encephalitis or cardiopulmonary failure. Encephalitis is caused by brain infection with EV71, and the pulmonary edema diagnosed in EV71-infected patients is a form of NPE. We now know that VEGF is responsible for the cross-talk between nerves and vessels and plays a crucial role in the nervous system [16]. However, the mechanism underlying EV71 infection and pulmonary edema remains unclear. It has been reported that EV71 infection induces cytokine secretion, e.g. IL-10, IL13 , IFN- $\gamma$, IL- 6 , TNF- $\alpha$ and IL-1 $\beta$, which increase the permeability of lung vessels and cause pulmonary edema $[17,18]$. Neural injury induces VEGF expression and VEGF overexpression in lung causes pulmonary edema [14]. Therefore, it is probable that in EV71-infected cells, including neuron, muscle, lung and heart cells, VEGF expression is induced, which is responsible for changes in lung cell permeability and pulmonary edema.

In this study, we initially revealed high VEGF expression in the sera of EV71-infected patients, indicating that VEGF may play pivotal roles in EV71-related CPE and NPE. Consistently, only active EV71 infection induces two isoforms (165 and 121) of VEGF mRNA expression in various tissue cell lines (muscle, neuron, lung and microvascular endothelial cell lines; fig. 3a-d). The increase in steady-state levels of VEGF RNA in hypoxia C6 (glioma cells) and PC12 cells resulted from both increased transcription and increased RNA stability [19-22]. It is also known that enterovirus infection induces HIF-1 expression, and HIF as a transcriptional factor may induce VEGF expression [23]. In contrast, hepatitis $C$ virus core protein induces TGF- $\beta_{2}$ expression, which utilizes JNK and p38 pathways to up-regulate VEGF proteins [24]. Surprisingly, VEGF protein expression in the above four cell lines was significantly decreased while infected with active EV71 6 and/or $12 \mathrm{~h}$ after infection (fig. $4 \mathrm{a}-\mathrm{d}$ ). The discrepancy between VEGF mRNA and protein expression in the four cell lines is possibly caused by increased delivery and/or fast degradation of VEGF protein caused by active EV71 infection. The possibility of increased delivery of VEGF was excluded by measuring VEGF protein expression in the culture media of EV71-infected cells (fig. 5). In summary, VEGF secretion was decreased in active EV71-infected muscle (RD) and neuronal (SK-N$\mathrm{SH})$ cells, but did not change in lung (A549) and micro- 
vascular endothelial cells (HMEC-1). Therefore, EV71 infection may induce the degradation of VEGF. Further research is needed to verify this possibility. Nonetheless, we demonstrated that in four EV71-infected cell lines VEGF protein expression was neither endogenously nor exogenously induced. The higher VEGF level in the serum of EV71-infected patients may not originate from the virus-infected cells. It is possible that the cytokines and unknown factors produced by EV71-infected cells are actually inducing increased VEGF expression in neighboring cells. It is also possible that EV71 induces HIF expression, which further increases VEGF expression in the neighboring cells via a paracrine pathway. Dengue virus infection increases the expression of Th1 and Th2 cytokines IL-4, IL-8, IL-6, IL-10, GM-CSF, INF- $\gamma$ and TNF- $\alpha$. These proinflammatory cytokines increase VEGF expression [25]. Due to the diverse cell types inside our body which may secrete VEGF, how precisely VEGF protein is secreted and the origin of increased VEGF secretion warrant further study. A mouse model of appropriate EV71 infection may enable researchers to obtain a more comprehensive understanding of the clinical roles of VEGF in EV71-infected patients.

\section{Acknowledgments}

This research was supported by the grants NSC 94-2320-B006-065, NSC 96-2628-B-006-003-MY3 and NSC 98-2745-B-006002 from the National Science Council, Taiwan, ROC. We also thank Mr. Peter Wilds for his critical editing of the manuscript.

\section{References}

1 Senger DR, Galli SJ, Dvorak AM, Perruzzi CA, Harvey VS, Dvorak HF: Tumor cells secrete a vascular permeability factor that promotes accumulation of ascites fluid. Science 1983;219:983-985.

- 2 Meyer M, Clauss M, Lepple-Wienhues A, Waltenberger J, Augustin HG, Ziche M, Lanz C, Buttner M, Rziha HJ, Dehio C: A novel vascular endothelial growth factor encoded by Orf virus, VEGF-E, mediates angiogenesis via signalling through VEGFR-2 (KDR) but not VEGFR-1 (Flt-1) receptor tyrosine kinases. EMBO J 1999;18:363-374.

3 Neufeld G, Cohen T, Gengrinovitch S, Poltorak Z: Vascular endothelial growth factor (VEGF) and its receptors. FASEB J 1999;13: 9-22.

-4 Ogawa S, Oku A, Sawano A, Yamaguchi S, Yazaki Y, Shibuya M: A novel type of vascular endothelial growth factor, VEGF-E (NZ7 VEGF), preferentially utilizes KDR/Flk-1 receptor and carries a potent mitotic activity without heparin-binding domain. J Biol Chem 1998;273:31273-31282.

5 Ferrara N, Gerber HP, LeCouter J: The biology of VEGF and its receptors. Nat Med 2003;9:669-676.

6 Ferrara N, Davis-Smyth T: The biology of vascular endothelial growth factor. Endocr Rev 1997;18:4-25.

-7 Torimura T, Sata M, Ueno T, Kin M, Tsuji R, Suzaku K, Hashimoto O, Sugawara H, Tanikawa K: Increased expression of vascular endothelial growth factor is associated with tumor progression in hepatocellular carcinoma. Hum Pathol 1998;29:986-991.

-8 Alon T, Hemo I, Itin A, Pe'er J, Stone J, Keshet $\mathrm{E}$ : Vascular endothelial growth factor acts as a survival factor for newly formed retinal vessels and has implications for retinopathy of prematurity. Nat Med 1995;1:1024-1028.
-9 Bell C, Lynam E, Landfair DJ, Janjic N, Wiles ME: Oligonucleotide NX1838 inhibits VEGF165-mediated cellular responses in vitro. In Vitro Cell Dev Biol Anim 1999;35: 533-542.

10 Monacci WT, Merrill MJ, Oldfield EH: Expression of vascular permeability factor/vascular endothelial growth factor in normal rat tissues. Am J Physiol 1993;264:C995-C1002.

11 Safran M, Kaelin WG Jr: HIF hydroxylation and the mammalian oxygen-sensing pathway. J Clin Invest 2003;111:779-783.

12 Grugel S, Finkenzeller G, Weindel K, Barleon B, Marme D: Both v-Ha-Ras and v-Raf stimulate expression of the vascular endothelial growth factor in NIH 3T3 cells. J Biol Chem 1995;270:25915-25919.

$>13$ Iliopoulos O, Levy AP, Jiang C, Kaelin WG Jr, Goldberg MA: Negative regulation of hypoxia-inducible genes by the von HippelLindau protein. Proc Natl Acad Sci USA 1996;93:10595-10599.

-14 Bartholdi D, Rubin BP, Schwab ME: VEGF mRNA induction correlates with changes in the vascular architecture upon spinal cord damage in the rat. Eur J Neurosci 1997;9: 2549-2560.

$\checkmark 15$ Yeh HH, Lai WW, Chen HH, Liu HS, Su WC; Autocrine IL-6-induced Stat3 activation contributes to the pathogenesis of lung adenocarcinoma and malignant pleural effusion. Oncogene 2006;25:4300-4309.

16 Ruiz de Almodovar C, Lambrechts D, Mazzone $\mathrm{M}$, Carmeliet P: Role and therapeutic potential of VEGF in the nervous system. Physiol Rev 2009;89:607-648.

17 Lin TY, Hsia SH, Huang YC, Wu CT, Chang LY: Proinflammatory cytokine reactions in enterovirus 71 infections of the central nervous system. Clin Infect Dis 2003;36:269274.
18 Wang SM, Lei HY, Huang KJ, Wu JM, Wang JR, Yu CK, Su IJ, Liu CC: Pathogenesis of enterovirus 71 brainstem encephalitis in pediatric patients: roles of cytokines and cellular immune activation in patients with pulmonary edema. J Infect Dis 2003; 188:564-570.

19 Ikeda E, Achen MG, Breier G, Risau W: Hypoxia-induced transcriptional activation and increased mRNA stability of vascular endothelial growth factor in C6 glioma cells. J Biol Chem 1995;270:19761-19766.

-20 Levy AP, Levy NS, Goldberg MA: Post-transcriptional regulation of vascular endothelial growth factor by hypoxia. J Biol Chem 1996;271:2746-2753.

-21 Levy AP, Levy NS, Wegner S, Goldberg MA: Transcriptional regulation of the rat vascular endothelial growth factor gene by hypoxia. J Biol Chem 1995;270:13333-13340.

-22 Stein I, Neeman M, Shweiki D, Itin A, Keshet E: Stabilization of vascular endothelial growth factor mRNA by hypoxia and hypoglycemia and coregulation with other ischemia-induced genes. Mol Cell Biol 1995;15: 5363-5368.

23 Forsythe JA, Jiang BH, Iyer NV, Agani F, Leung SW, Koos RD, Semenza GL: Activation of vascular endothelial growth factor gene transcription by hypoxia-inducible factor 1. Mol Cell Biol 1996;16:4604-4613.

-24 Hassan M, Selimovic D, Ghozlan H, Abdelkader O: Hepatitis $\mathrm{C}$ virus core protein triggers hepatic angiogenesis by a mechanism including multiple pathways. Hepatology 2009;49:1469-1482.

-25 Azizan A, Sweat J, Espino C, Gemmer J, Stark L, Kazanis D: Differential proinflammatory and angiogenesis-specific cytokine production in human pulmonary endothelial cells, HPMEC-ST1.6R infected with dengue-2 and dengue-3 virus. J Virol Methods 2006;138:211-217. 